\title{
PEMODELAN STUDI KASUS VACUUM PRELOADING UNTUK MEMPREDIKSI PENURUNAN BERDASARKAN DATA PENGAMATAN PADA TANAH REKLAMASI
}

\author{
Andi Sulistio ${ }^{1}$, Inda Sumarli ${ }^{2}$, dan Ali Iskandar ${ }^{3}$ \\ ${ }^{1}$ Program Studi Sarjana Teknik Sipil, Universitas Tarumanagara, Jl. Letjen S. Parman No.1 Jakarta \\ andi.sulistio15@gmail.com \\ ${ }^{2}$ Program Studi Sarjana Teknik Sipil, Universitas Tarumanagara, Jl. Letjen S. Parman No.1 Jakarta \\ indasumarli@gmail.com \\ ${ }^{3}$ Program Studi Sarjana Teknik Sipil, Universitas Tarumanagara, Jl. Letjen S. Parman No.1 Jakarta \\ ali.iskandar1999@gmail.com
}

\begin{abstract}
Reclamation is the process of making new land by landfill, previously land are used to edge of the sea, riverbeds, lake beds or pond area. With the initial soil condition that contains a lot of water, it is necessary to remove the existing water content so that the capacity of the soil is sufficient to occupy the planned capacity. The objective strength accordance with the new functional land, which in this study case is planned to be used for highway. One of the most effective ways is soil vacuum preloading to increase the soil capacity. This system is done by inserting sheets which are filled with plastic sheets and wrapped in geotextiles so that soil particles will not be sucked up. This method is generally assisted by additional loads on the ground surface such as heap or surcharge water load to increase the pressure which applied to the soil. The analysis carried out was taken from the toll road construction project in the North Jakarta area which was carried out on the reclamation land area. In this case study modeling, the depth of prefabricated vertical drain used an average of 14 meters with distance of every 1 meter.
\end{abstract}

Keywords: vacuum preloading; settlement; finite element method (2D); Mohr-Coulomb; soft soil

\begin{abstract}
ABSTRAK
Reklamasi merupakan proses pembuatan lahan baru dengan melakukan penimbunan tanah, dimana sebelumnya lahan dapat merupakan area pinggir laut, sungai, maupun tambak. Dengan kondisi awal lahan yang banyak mengandung air, diperlukan proses mengeluarkan kadar air yang ada agar daya dukung tanah memenuhi kekuatan yang direncanakan. Daya dukung disesuaikan dengan fungsional baru lahan, dalam studi kasus ini difungsikan sebagai landasan jalan tol. Salah satu cara paling efektif dalam memperbaiki tanah reklamasi adalah menggunakan sistem vacuum preloading. Sistem ini dilakukan dengan memasukkan lembaran yang dalamnya berisi lembaran plastik dan dibungkus dengan geotekstil agar partikel tanah dapat tidak ikut terhisap. Lembaran ini digunakan sebagai media untuk jalur menghisap air menggunakan mesin vakum. Pada umumnya proses ini dibantu dengan tambahan beban pada permukaan tanah seperti timbunan atau genangan air untuk menambah tekanan yang diberikan pada tanah. Semakin besar tekanan yang diberikan ke tanah, maka akan mempercepat proses konsolidasi atau keluarnya air dari dalam tanah. Analisis dilakukan pada proyek pembangunan jalan tol di Jakarta Utara yang dilakukan diatas area lahan reklamasi. Pada pemodelan studi kasus ini kedalaman prefabricated vertical drain yang digunakan rata-rata 14 meter dengan jarak setiap 1 meter. Analisis penurunan menggunakan program elemen hingga 2 dimensi dengan metode Mohr-Coulomb dan soft soil.
\end{abstract}

Kata kunci: vacuum preloading; penurunan; program elemen hingga (2D); Mohr-Coulomb; soft soil

\section{PENDAHULUAN}

Dengan seiring berjalannya waktu, kebutuhan lahan pada kota-kota besar terus meningkat dengan pesat hal ini menyebabkan terjadinya kekurangan lahan. Hal ini yang mendorong para pengembang untuk melakukan pelebaran lahan, salah satunya dengan melakukan penimbunan tanah secara luas pada kawasan seperti pinggir laut, sungai, maupun rawa. Kegiatan ini disebut juga dengan reklamasi. Kondisi awal tanah pada lahan reklamasi, umumnya merupakan tanah lempung sangat lunak yang memiliki daya dukung rendah dan mengandung kadar air yang tinggi. Sedangkan, tanah merupakan dasar dari sebuah pekerjaan konstruksi, baik itu pekerjaan konstruksi rumah, 
apartemen, jembatan, jalan raya, dan sebagainya. Tanah diharuskan dapat menanggung beban struktur atas, sehingga bangunan di atasnya terhindar dari kerusakan atau penurunan.

Hal ini menyebabkan tanah reklamasi perlu dilakukan perbaikan agar kekuatan tanah dapat memenuhi syarat yang dibutuhkan untuk menopang struktur di atasnya. Metode perbaikan tanah dapat dilakukan dengan berbagai macam cara. Metode yang umum dilakukan di Indonesia adalah metode tumbukan, vibroflotation, vertical drain, dan vacuum pre-loading. Perbaikan tanah pada lokasi yang ditinjau, menggabungkan metode vacuum preloading dengan vertical drain untuk mempercepat proses konsolidasi.

Metode Prefabricated Vertical Drain (PVD) adalah metode perbaikan dengan cara menanamkan lembaran membran sintetis ke dalam tanah untuk menjadi jalur keluar air dan udara dari dalam tanah. Metode vacuum preloading adalah perbaikan dengan cara memberikan timbunan dengan beratnya minimal setara dengan berat rencana sehingga memberikan tekanan pada tanah dan melakukan vakum dengan tekanan pompa sehingga mempercepat proses keluarnya air dan udara sehingga mendukung terjadinya proses konsolidasi.

Perbaikan tanah yang dilakukan bertujuan untuk mencapai daya dukung perlu dan penurunan tanah sudah mendekati penurunan akhir sehingga struktur atas bangunan tidak mengalami penurunan di kemudian hari. Berdasarkan beberapa pertimbangan tersebut, maka dilakukan penelitian untuk memprediksi durasi proses perbaikan tanah yang dibutuhkan untuk tanah mencapai penurunan akhir melalui pemodelan pada program elemen hingga. Dengan demikian, judul dari penelitian yang akan dilakukan adalah "Pemodelan Studi Kasus Vacuum Preloading Untuk Memprediksi Penurunan Berdasarkan Data Pengamatan Pada Tanah Reklamasi Jakarta Utara”.

Penulis menganalisis besar penurunan dan durasi penurunan menggunakan perhitungan manual dan program elemen hingga 2D, dengan metode Mohr-Coulomb dan soft soil. Penelitian yang dilakukan perlu dibatasi agar fokus permasalahan dan tujuan penelititan dapat tercapai. Adapun batasan-batasan pada penelitian ini adalah sebagai berikut, lokasi dari studi kasus yang diteliti merupakan proyek perbaikan tanah reklamasi untuk jalan tol di Jakarta Utara, data tanah didapat dari hasil penelitian yang dilakukan oleh pihak kontraktor, metode perbaikan dilakukan dengan dua metode, vacuum pre-loading dan vertical drain, Analisis perbaikan tanah dalam kondisi undrained, dilakukan analisis penurunan pada tanah reklamasi menggunakan bantuan program elemen hingga $2 \mathrm{D}$.

Berdasarkan uraian yang telah dituliskan di atas, masalah awal yang harus diselesaikan penulis adalah melakukan korelasi terhadap hasil uji tes tanah sehingga mendapatkan batasan-batasan dari tiap nilai parameter tanah. Setelah mendapatkan kesimpulan dari korelasi parameter, nilai tersebut akan dimasukkan ke dalam program dan digunakan dalam perhitungan manual untuk dilakukan analisis.

Tujuan akhir dari penelitian ini adalah mengetahui berapa durasi yang dibutuhkan untuk tanah reklamasi tersebut mencapai terkonsolidasi $90 \%$ dan juga menganalisis besar penurunan yang terjadi sehingga data analisis dapat digunakan sebagai refrensi dalam mengerjakan perbaikan pada zona lainnya di proyek jalan tol Jakarta Utara ini.

\section{Modulus elastisitas}

Modulus elastisitas adalah besaran yang menggambarkan tingkat elastisitas bahan, membandingkan antara nilai tegangan terjadi terhadap regangan. Nilai ini menunjukkan batas kemampuan tanah mempertahankan bentuk aslinya apabila beban di hilangkan. Nilai Es didapatkan dari hasil tes trixial. Sedangkan untuk beberapa jenis tanah nilai modulus elastisitas secara empiris dapat diperoleh dari data sondir dan SPT. (Das, 1995)

\section{Over-consolidated ratio (OCR)}

OCR adalah angka yang menunjukan nilai banding antara tekanan prakonsolidasi (pc') dengan tegangan efektif yang ada sekarang.

$$
O C R=\frac{p_{c^{\prime}}}{p_{0^{\prime}}}
$$

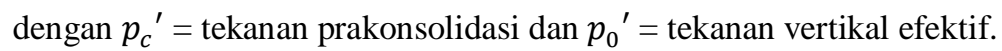

\section{Penurunan konsolidasi}

Terdapat 2 jenis pembagian penurunan konsolidasi berdasarkan teori dari (Terzaghi, 1965) yakni tanah Normally Consolidated dan Over Consolidated.

Tanah Normally Consolidated, nilai OCR $=1$ :

$$
S c=\frac{C c H}{1+e o} \log \left(\frac{P o+\Delta P}{P o}\right)
$$


dengan $\mathrm{H}=$ tebal lapisan, eo $=$ angka pori awal, $P o=$ tekanan efektif overburden untuk sub-lapisan dan $\Delta \mathrm{P}=$ penambahan tekanan vertikal untuk sub-lapisan.

Tanah Over Consolidated, dimana nilai OCR > 1:

- $\quad$ Apabila $\mathrm{Po}+\Delta \mathrm{P}<\mathrm{Pc}$

$$
S c=\left(\frac{C s}{1+e o} \log \left(\frac{P o+\Delta P}{P o}\right)\right)
$$

- Apabila $\mathrm{Po}+\Delta \mathrm{P}>\mathrm{Pc}$

$$
S c=\left(\frac{C s}{1+e o} \log \left(\frac{P c}{P o}\right)+\frac{C c H}{1+e o} \log \left(\frac{P o+\Delta P}{P C}\right)\right)
$$

dengan $\mathrm{Cs}=$ indeks pemuaian, $\mathrm{Cc}=$ indeks pemampatan, $\mathrm{H}=$ tebal lapisan, eo = angka pori awal, $P o=$ tekanan efektif overburden dan $P c=$ tekanan prakonsolidasi.

\section{Penurunan elastis}

Penurunan elastis merupakan akibat dari deformasi elastis tanah kering, basah, dan jenuh air tanpa adanya perubahan kadar air. Perhitungan penurunan segera umunya didasarkan pada penurunan yang diturunkan dari teori elastisitas. Besar penurunan elastis dapat dihitung dengan rumus sebagai berikut. (Gunawan, et. al., 2020)

$$
S i=\frac{\Delta \sigma}{M} H
$$

dengan $\Delta \sigma=$ tegangan total dan $\mathrm{M}=$ constrained modulus.

\section{Waktu penurunan}

Waktu yang dibutuhkan tanah untuk proses konsolidasi, didapatkan dari:

$$
\mathrm{t} 90=\operatorname{Tr} \mathrm{x} \frac{4 \cdot \mathrm{H}^{2}}{\mathrm{Ch}}
$$

dengan $\mathrm{Cv}=$ koefisien konsolidasi horizontal, $\mathrm{H}=$ tinggi contoh uji sesuai kondisi drainase, $\mathrm{Tr}=$ faktor waktu dan $t_{90}=$ waktu pada tanah $90 \%$ terkonsolidasi.

\section{Metode vacuum pre-loading}

Metode vacuum preloading awalnya diperkenalkan oleh Kjellman pada tahun 1952 dan dikerjakan oleh Royal Swedish Geotechnical Institute sebagai metode untuk memperbaiki tanah biji-bijian halus. Pada dasarnya metode ini dilakukan dengan memasang lapisan membran yang kedap udara diatas tanah yang akan dilakukan konsolidasi dan kemudian diciptakan kondisi vakum di bawah membran (Gambar 1 dan Gambar 2).

Dengan system tersebut maka akan dicapai tekanan atmosfir sebesar 1 atm atau setara dengan $100 \mathrm{kN} / \mathrm{m}^{2}$ pada mesin. Diasumsikan efisiensi dari alat sebesar $70 \%$ di bawah vacuum sheet sehingga menciptakan tekanan sebesar $70 \mathrm{kN} / \mathrm{m}^{2}$ yang sebanding dengan preloading setinggi $4 \mathrm{~m}$. Diameter yang digunakan pada pola pemasangan PVD dapat dihitung dengan persamaan:

Pola Segiempat:

$$
\mathrm{D}=1,13 \mathrm{~S}
$$

Pola Segitiga:

$$
\mathrm{D}=1,05 \mathrm{~S}
$$

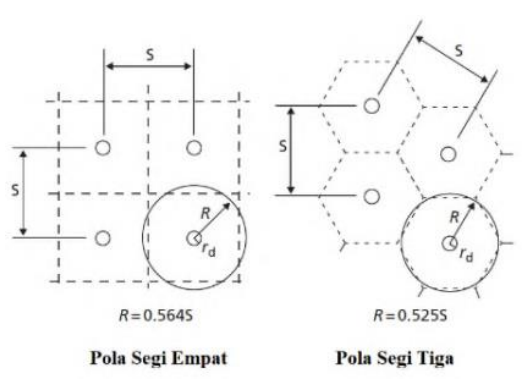

Gambar 1. Pola pemasangan PVD (Sumber: Sakleshpur, 2018) 


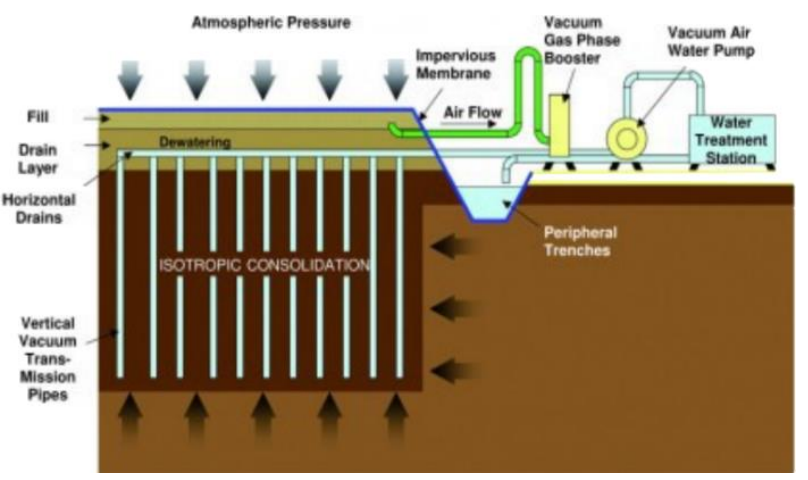

Gambar 2. Sistem vacuum preloading (Sumber: Massè, 2001)

\section{Metode vertical drain}

Pemakaian sistem vertical drain dilakukan agar dapat mempercepat waktu penurunan konsolidasi yang cenderung lama. Pada prinsipnya drainase ini dapat dikatakan menjamin aliran air tanpa kecil hambatan ke arah lapisan porus yang berada di atas muka tanah atau bahkan dua lapisan porus di atas dan di bawah lapisan lunak (berada dalam tanah) dan juga tidak menimbulkan masalah pada bidang kontak antara tanah dan drain. (Chai, 2001)

Vertical drain dapat dipergunakan dalam berbagai aplikasi, diantaranya di bawah embankment jalan raya, jalan kereta api atau landas pacu pesawat serta di bawah pondasi tanki minyak yang berdiri di atas tanah lunak, dan pada konstruksi-konstruksi lainnya. Vertikal drain terutama digunakan untuk membantu proses konsolidasi sehingga pada waktu konstruksi yang sebenarnya didirikan, tidak akan mengalami penurunan yang berlebihan yang dapat menyebabkan gangguan operasi sarana-sarana tersebut (Gambar 3).

Vertikal drain sintetis umumya berbentuk strip dan terdiri dari dua komponen utama yaitu inti plastik yang dibungkus dengan material geosintetis. Inti plastik berfungsi sebagai penyalur air dan pembungkus sebagai filter bagi partikel tanah halus. Pola pemasangan drainase vertikal yang biasa dipakai adalah pola segitiga dan pola segi empat.

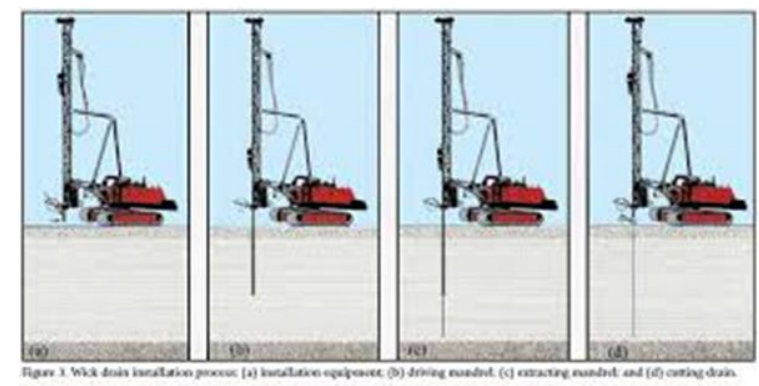

Gambar 3. Proses pengerjaan vertikal drain (Sumber: Bergardo, 1996)

\section{METODE PENELITIAN}

\section{Pengumpulan data}

Pengumpulan data hasil tes tanah didapatkan oleh penulis dari pihak kontraktor yang bertanggung jawab atas proyek perbaikan tanah ini. Data tanah yang digunakan merupakan data tanah pada zona 2. Hasil uji data lab, CPT, dan boring log yang berada dekat dengan titik settlement plate yang mengalami penurunan tersebesar digunakan sebagai data awal untuk selanjutnya dilakukan korelasi parameter dan perhitungan.

\section{Pengolahan data}

Pada proses pengolahan data, penulis melakukan korelasi nilai parameter berdasarkan data hasil uji tes tanah. Parameter yang dilakukan korelasi merupakan parameter yang dibutuhkan untuk dapat menghitung menggunakan program elemen hingga 2D dengan dua metode rencana yaitu Mohr-Coulomb dan soft soil. Nilai-nilai yang dibutuhkan dalam perhitungan manual juga dihitung agar dapat dilakukan analisis perhitungan durasi dan besar penurunan secara manual. 


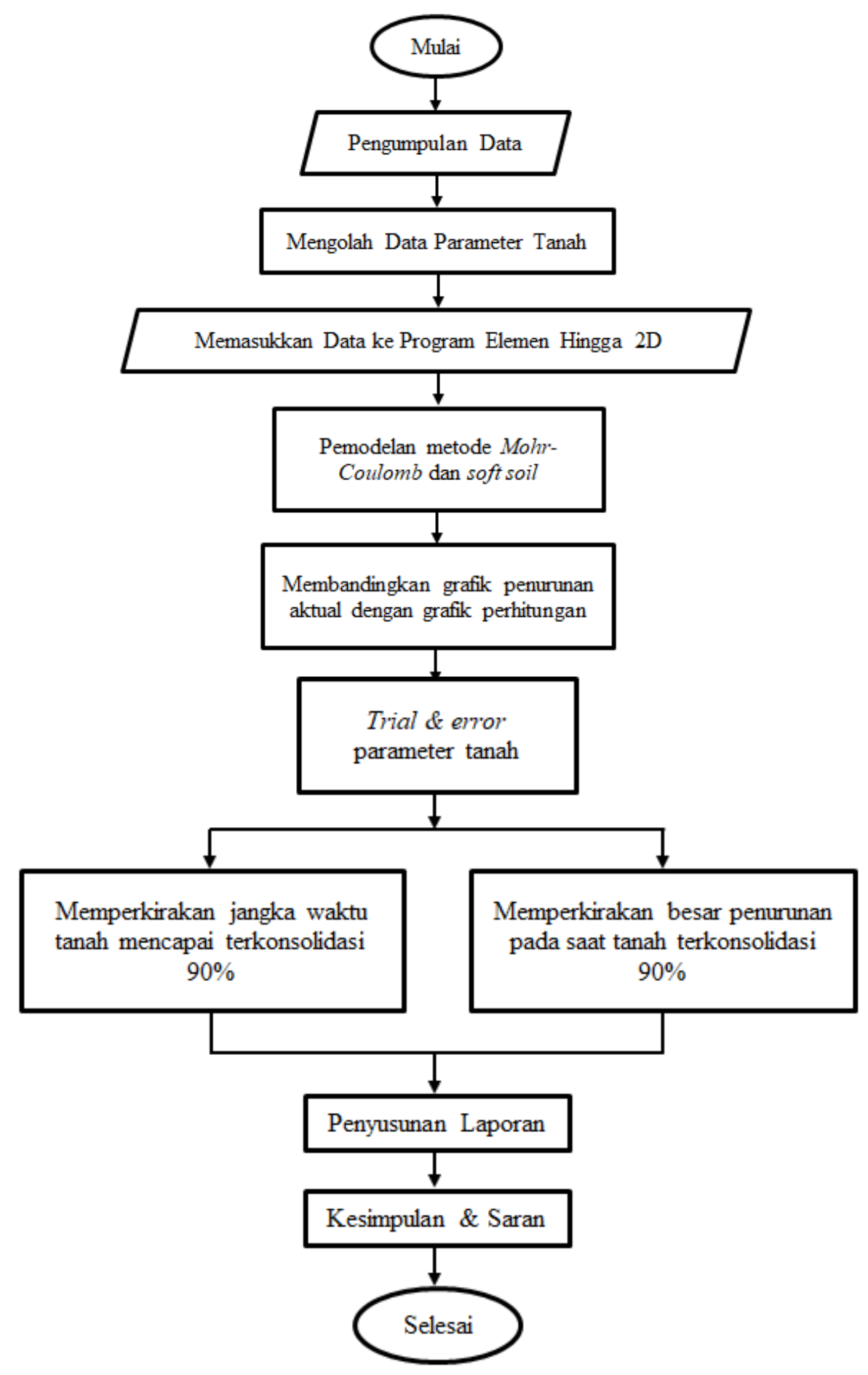

Gambar 4. Diagram alir penelitian

\section{HASIL DAN PEMBAHASAN}

\section{Analisis lapisan tanah pada zona 2}

Berdasarkan data uji tes tanah dikelompokan nilai N-spt lapisan tanah terbagi menjadi 7 lapisan dengan nilai N-spt dan konsistensi sebagai berikut (Tabel 1). 
Pemodelan Studi Kasus Vacuum Preloading untuk Andi Sulistio, et al. Memprediksi Penurunan Berdasarkan Data Pengamatan pada Tanah Reklamasi

Tabel 1. Data lapisan tanah zona 2 proyek jalan tol

\begin{tabular}{ccccc}
\hline $\begin{array}{c}\text { Lapisan } \\
\text { Tanah }\end{array}$ & $\begin{array}{c}\text { Kedalaman } \\
(\mathbf{m})\end{array}$ & N-SPT & Jenis Tanah & $\begin{array}{c}\text { Konsistensi } \\
\text { Tanah }\end{array}$ \\
\hline Lapisan 1 & $0-8$ & 2 & Silty Clay & Very Soft \\
Lapisan 2 & $8-13$ & 4 & Silty Clay & Soft \\
Lapisan 3 & $13-22$ & 14 & Clayey Silt & Stiff \\
Lapisan 4 & $22-32$ & 18 & Silty Clay & Stiff \\
Lapisan 5 & $32-35$ & 22 & Silty Clay & Very Stiff \\
Lapisan 6 & $35-39$ & 32 & Sandy Silt & Very Stiff \\
Lapisan 7 & $39-60$ & 26 & Silty Clay & Very Stiff \\
\hline
\end{tabular}

Hasil korelasi parameter didapatkan untuk input ke program elemen hingga dengan mencakup parameter untuk metode Mohr-Coulomb dan soft soil. Berikut merupakan rangkuman parameter yang didapat (Tabel 2-Tabel 4):

Tabel 2. Rangkuman hasil korelasi parameter tanah (a)

\begin{tabular}{|c|c|c|c|c|c|c|}
\hline $\begin{array}{c}\text { Lapisan } \\
\text { Tanah }\end{array}$ & $\begin{array}{c}\text { Kedalaman } \\
\text { (m) }\end{array}$ & Jenis Tanah & $\begin{array}{c}\gamma_{\text {unsat }} \\
(\mathrm{kN} / \mathrm{m3})\end{array}$ & $\begin{array}{c}\gamma_{s a t} \\
\left(\mathbf{k N} / \mathbf{m}^{3}\right)\end{array}$ & k (m/sec) & $\begin{array}{c}\mathrm{E} \\
\left(\mathrm{kg} / \mathrm{cm}^{2}\right)\end{array}$ \\
\hline Lapisan 1 & $0-8$ & Silty Clay & 14,5 & 14,8 & $1 \times 10^{-7}$ & 4000 \\
\hline Lapisan 2 & $8-13$ & Silty Clay & 14,8 & 16 & $1 \times 10^{-6}$ & 8000 \\
\hline Lapisan 3 & $13-22$ & Clayey Silt & 16,5 & 17,5 & $1 \times 10^{-6}$ & 11000 \\
\hline Lapisan 4 & $22-32$ & Silty Clay & 17,2 & 19 & $1 \times 10^{-7}$ & 9000 \\
\hline Lapisan 5 & $32-35$ & Silty Clay & 17,6 & 18,5 & $1 \times 10^{-7}$ & 8000 \\
\hline Lapisan 6 & $35-39$ & Sandy Silt & 18 & 21 & $1 \times 10^{-5}$ & 8000 \\
\hline Lapisan 7 & $39-60$ & Silty Clay & 18 & 20 & $1 \times 10^{-7}$ & 10000 \\
\hline
\end{tabular}

Tabel 3. Rangkuman hasil korelasi parameter tanah (b)

\begin{tabular}{ccccccc}
\hline $\begin{array}{c}\text { Lapisan } \\
\text { Tanah }\end{array}$ & $\begin{array}{c}\text { Kedalaman } \\
(\mathbf{m})\end{array}$ & Jenis Tanah & $\mathbf{v}$ & $\mathbf{C}\left(\mathbf{k N} / \mathbf{m}^{\mathbf{2}}\right)$ & $\boldsymbol{\phi ( \mathbf { o } ^ { \mathbf { * } } )}$ & $\boldsymbol{\Psi}\left(^{\mathbf{0}}\right)$ \\
\hline Lapisan 1 & $0-8$ & Silty Clay & 0,48 & 12 & 30 & 0 \\
Lapisan 2 & $8-13$ & Silty Clay & 0,45 & 20 & 30 & 0 \\
Lapisan 3 & $13-22$ & Clayey Silt & 0,4 & 30 & 35 & 5 \\
Lapisan 4 & $22-32$ & Silty Clay & 0,4 & 48 & 30 & 0 \\
Lapisan 5 & $32-35$ & Silty Clay & 0,4 & 33 & 30 & 0 \\
Lapisan 6 & $35-39$ & Sandy Silt & 0,4 & 45 & 30 & 0 \\
Lapisan 7 & $39-60$ & Silty Clay & 0,4 & 68 & 30 & 0 \\
\hline
\end{tabular}


Tabel 4. Rangkuman hasil korelasi parameter tanah (c)

\begin{tabular}{cccccccc}
\hline $\begin{array}{c}\text { Lapisan } \\
\text { Tanah }\end{array}$ & $\begin{array}{c}\text { Kedalaman } \\
(\mathbf{m})\end{array}$ & Jenis Tanah & Cc & Cs & Pc (KPa) & OCR & Rinter \\
\hline Lapisan 1 & $0-8$ & Silty Clay & 2,1 & 0,35 & 130 & 1 & 1 \\
Lapisan 2 & $8-13$ & Silty Clay & 1,5 & 0,2 & 300 & 2 & 1 \\
Lapisan 3 & $13-22$ & Clayey Silt & 0,5 & 0,08 & 650 & 3 & 1 \\
Lapisan 4 & $22-32$ & Silty Clay & 1 & 0,16 & 1000 & 3,5 & 1 \\
Lapisan 5 & $32-35$ & Silty Clay & 0,85 & 0,14 & 1250 & 3,5 & 1 \\
Lapisan 6 & $35-39$ & Sandy Silt & 0,7 & 0,12 & 1500 & 4 & 1 \\
Lapisan 7 & $39-60$ & Silty Clay & 0,7 & 0,12 & 1250 & 4 & 1 \\
\hline
\end{tabular}

\section{Perhitungan menggunakan program elemen hingga 2D, metode Mohr-Coulomb}

Perhitungan dalam program elemen hingga dilakukan secara trial and error untuk dapat memformulasikan parameter tanah agar hasil penurunan yang didapat menyerupai hasil penurunan monitoring yang sudah terjadi pada lokasi proyek. Nilai modulus elastisitas merupakan parameter yang memiliki dampak yang paling signifikan dalam mempengaruhi besar penurunan yang terjadi. Tabel 5 merupakan batasan hasil korelasi dan penggunaan nilai modulus elastis yang digunakan.

Tabel 5. Perbandingan nilai E korelasi dengan hasil trial and error

\begin{tabular}{|c|c|c|c|c|c|}
\hline Lapisan Tanah & $\begin{array}{c}\text { Kedalaman } \\
\text { (m) }\end{array}$ & $\begin{array}{c}\text { Batas } \\
\text { Minimal } \\
\text { E }\end{array}$ & $\begin{array}{c}\text { Batas } \\
\text { Maksimal } \\
\text { E }\end{array}$ & $\begin{array}{c}\text { E Korelasi } \\
\left(\mathbf{k N} / \mathbf{m}^{2}\right)\end{array}$ & $\begin{array}{c}\text { E Program } \\
\text { Elemen } \\
\text { Hingga }\end{array}$ \\
\hline Lapisan 1 & $0-8$ & 2000 & 10000 & 4000 & 1400 \\
\hline Lapisan 2 & $8-13$ & 2000 & 8000 & 8000 & 2800 \\
\hline Lapisan 3 & $13-22$ & 3500 & 10000 & 11000 & 3850 \\
\hline Lapisan 4 & $22-32$ & 8000 & 10000 & 9000 & 9000 \\
\hline Lapisan 5 & $32-35$ & 6000 & 9000 & 8000 & 8000 \\
\hline Lapisan 6 & $35-39$ & 7000 & 10000 & 8000 & 8000 \\
\hline Lapisan 7 & $39-60$ & 10000 & 10000 & 10000 & 10000 \\
\hline
\end{tabular}

Setelah dilakukan perubahan nilai $\mathrm{E}$, hasil akhir penurunan program elemen hingga sudah mendekati penurunan akhir monitoring, namun untuk melandaikan hasil kurva penurunan program elemen hingga maka diperlukan trial and error nilai permeabilitas. Pendekatan dalam trial and error permeabilitas dilakukan pada 4 lapisan teratas. Nilai pemeabiltas yang digunakan dalam program elemen hingga dapat dilihat pada Tabel 6. 
Pemodelan Studi Kasus Vacuum Preloading untuk Memprediksi Penurunan Berdasarkan Data Pengamatan pada Tanah Reklamasi

Tabel 6. Perbandingan nilai permeabilitas korelasi dengan hasil trial and error

\begin{tabular}{cccccc}
\hline Lapisan Tanah & $\begin{array}{c}\text { Kedalaman } \\
(\mathbf{m})\end{array}$ & $\begin{array}{c}\text { Batas } \\
\text { Minimal } \\
\mathbf{k}\end{array}$ & $\begin{array}{c}\text { Batas } \\
\text { Maksimal k }\end{array}$ & $\begin{array}{c}\text { ky Korelasi } \\
(\mathbf{m} / \text { day })\end{array}$ & $\begin{array}{c}\text { kx Program } \\
\text { Elemen } \\
\text { Hingga }\end{array}$ \\
\hline Lapisan 1 & $0-8$ & $8,6 \times 10^{-5}$ & $8,6 \times 10^{-1}$ & $8,6 \times 10^{-5}$ & $2,6 \times 10^{-4}$ \\
Lapisan 2 & $8-13$ & $8,6 \times 10^{-5}$ & $8,6 \times 10^{-2}$ & $8,6 \times 10^{-4}$ & $2,6 \times 10^{-3}$ \\
Lapisan 3 & $13-22$ & $8,6 \times 10^{-5}$ & $8,6 \times 10^{-1}$ & $8,6 \times 10^{-4}$ & $2,6 \times 10^{-3}$ \\
Lapisan 4 & $22-32$ & $8,6 \times 10^{-5}$ & $8,6 \times 10^{-4}$ & $8,6 \times 10^{-5}$ & $2,6 \times 10^{-4}$ \\
Lapisan 5 & $32-35$ & $8,6 \times 10^{-5}$ & $8,6 \times 10^{-4}$ & $8,6 \times 10^{-5}$ & $2,6 \times 10^{-4}$ \\
Lapisan 6 & $35-39$ & $1,7 \times 10^{-4}$ & $8,6 \times 10^{-1}$ & $8,6 \times 10^{-3}$ & $2,6 \times 10^{-2}$ \\
Lapisan 7 & $39-60$ & $8,6 \times 10^{-5}$ & $8,6 \times 10^{-5}$ & $8,6 \times 10^{-5}$ & $2,6 \times 10^{-4}$ \\
\hline
\end{tabular}

Gambar 5 merupakan curve matching antara hasil penurunan program dengan data penurunan monitoring. Data penurunan monitoring terdapat 3 grafik, grafik dengan warna jingga merupakan penurunan terbesar pada zona 2 yang terjadi di area settlement plate ke-1. Grafik warna abu-abu merupakan penurunan terendah pada zona 2 yang terjadi pada area settlement plate ke-5. Grafik warna biru merupakan rata-rata penurunan dari kedua settlement plate tersebut dengan hasil akhir penurunan sebesar $638 \mathrm{~mm}$. Hasil perhitungan penurunan program adalah grafik dengan warna hitam dengan hasil akhir penurunan sebesar $611 \mathrm{~mm}$.

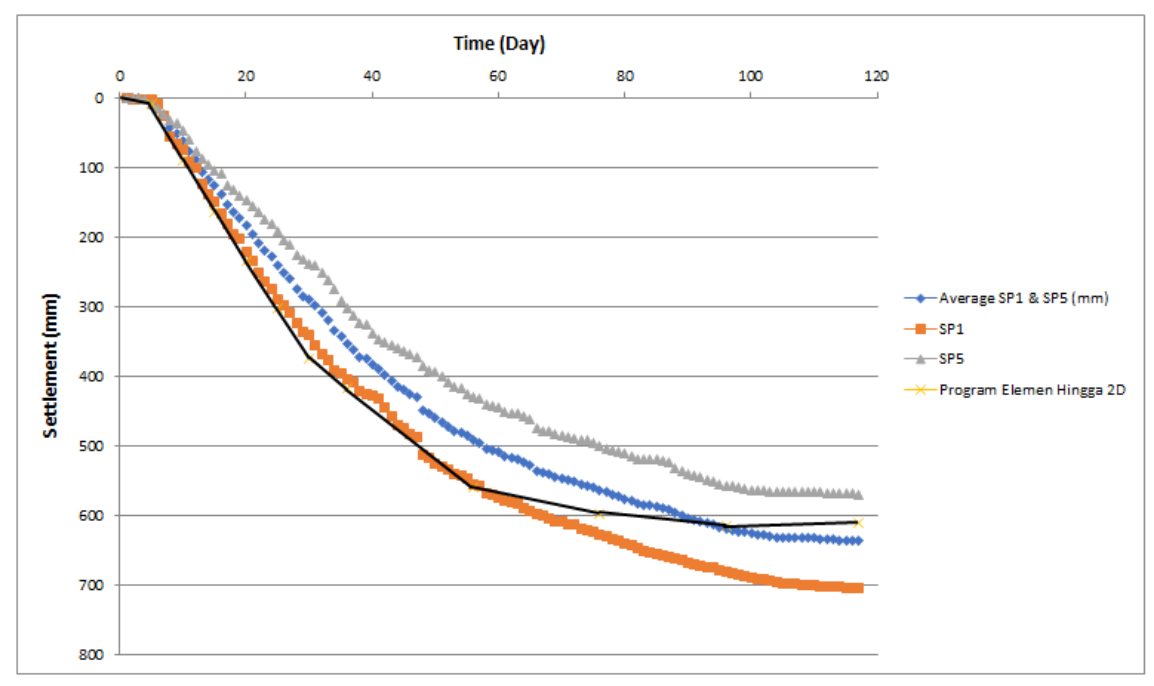

Gambar 5. Perbandingan penurunan monitoring lapangan dengan penurunan program elemen hingga 2D dengan metode Mohr-Coulomb

\section{Perhitungan menggunakan program elemen hingga 2D, metode soft soil}

Perhitungan metode soft soil dengan program elemen hingga 2D juga dilakukan secara trial and error untuk memperkirakan data parameter tanah yang tepat agar hasil penurunan yang didapat mendekati hasil penurunan monitoring. Parameter utama yang dilakukan trial and error adalah nilai indeks pemampatan (Cc), semakin besar nilai indeks pemampatan dari sebuah lapisan, maka lapisan tersebut akan mengalami penurunan yang lebih besar. Trial and error nilai Cc dilakukan pada 3 lapisan teratas, karena ketiga lapisan tersebut dominan terjadi penurunan. Percobaan nilai Cc juga berdasarkan nilai minimum dan maksimum dari korelasi yang dilakukan pada tahap awal perencanaan. Pengambilan nilai indeks pemampatan dapat dilihat pada Tabel 7. 
Tabel 7. Perbandingan korelasi nilai indeks pemampatan dengan hasil trial and error

\begin{tabular}{cccccc}
\hline Lapisan Tanah & $\begin{array}{c}\text { Kedalaman } \\
(\mathbf{m})\end{array}$ & $\begin{array}{c}\text { Batas } \\
\text { Minimal } \\
\mathbf{C c}\end{array}$ & $\begin{array}{c}\text { Batas } \\
\text { Maksimal } \\
\text { Cc }\end{array}$ & Korelasi Cc & $\begin{array}{c}\text { Cc Program } \\
\text { Elemen } \\
\text { Hingga }\end{array}$ \\
\hline Lapisan 1 & $0-8$ & 0,8 & 2,1 & 2,1 & 1,6 \\
Lapisan 2 & $8-13$ & 0,8 & 2,35 & 1,5 & 1,1 \\
Lapisan 3 & $13-22$ & 0,45 & 1,2 & 0,5 & 0,08 \\
Lapisan 4 & $22-32$ & 0,4 & 1 & 1 & 0,16 \\
Lapisan 5 & $32-35$ & 0,4 & 0,8 & 0,85 & 0,14 \\
Lapisan 6 & $35-39$ & 0,3 & 0,7 & 0,7 & 0,12 \\
Lapisan 7 & $39-60$ & 0,6 & 0,7 & 0,7 & 0,12 \\
\hline
\end{tabular}

Setelah dilakukan perubahan nilai Cc, hasil penurunan yang didapat dari program elemen hingga $2 \mathrm{D}$ mendekati penurunan akhir monitoring, dengan selisih penurunan hanya $4 \mathrm{~mm}$. Untuk menyesuaikan lengkungan kurva penurunan monitoring perlu dilakukan trial and error parameter nilai permeabilitas kembali yang dilakukan pada 4 lapisan teratas. Diasumsikan nilai permeabilitas arah x dan arah y memiliki tingkat permeabilitas yang sama. Nilai permeabiltas yang digunakan dalam program elemen hingga dapat dilihat pada Tabel 8.

Tabel 8. Perbandingan korelasi nilai permeabilitas dengan hasil trial and error

\begin{tabular}{cccccc}
\hline Lapisan Tanah & $\begin{array}{c}\text { Kedalaman } \\
(\mathbf{m})\end{array}$ & $\begin{array}{c}\text { Batas } \\
\text { Minimal k }\end{array}$ & $\begin{array}{c}\text { Batas } \\
\text { Maksimal k }\end{array}$ & $\begin{array}{c}\text { ky Korelasi } \\
(\mathbf{m} / \mathbf{d a y})\end{array}$ & $\begin{array}{c}\text { kx Program } \\
\text { Elemen } \\
\text { Hingga }\end{array}$ \\
\hline Lapisan 1 & $0-8$ & $8,6 \times 10^{-5}$ & $8,6 \times 10^{-1}$ & $8,6 \times 10^{-5}$ & $2,6 \times 10^{-4}$ \\
Lapisan 2 & $8-13$ & $8,6 \times 10^{-5}$ & $8,6 \times 10^{-2}$ & $8,6 \times 10^{-4}$ & $2,6 \times 10^{-3}$ \\
Lapisan 3 & $13-22$ & $8,6 \times 10^{-5}$ & $8,6 \times 10^{-1}$ & $8,6 \times 10^{-4}$ & $2,6 \times 10^{-3}$ \\
Lapisan 4 & $22-32$ & $8,6 \times 10^{-5}$ & $8,6 \times 10^{-4}$ & $8,6 \times 10^{-5}$ & $2,6 \times 10^{-4}$ \\
Lapisan 5 & $32-35$ & $8,6 \times 10^{-5}$ & $8,6 \times 10^{-4}$ & $8,6 \times 10^{-5}$ & $2,6 \times 10^{-4}$ \\
Lapisan 6 & $35-39$ & $1,7 \times 10^{-4}$ & $8,6 \times 10^{-1}$ & $8,6 \times 10^{-3}$ & $2,6 \times 10^{-2}$ \\
Lapisan 7 & $39-60$ & $8,6 \times 10^{-5}$ & $8,6 \times 10^{-5}$ & $8,6 \times 10^{-5}$ & $2,6 \times 10^{-4}$ \\
\hline
\end{tabular}


Gambar 6 merupakan hasil curve matching antara hasil penurunan program dengan data penurunan monitoring sebagai berikut. Grafik warna biru merupakan data penurunan monitoring dengan penurunan akhir sebesar $638 \mathrm{~mm}$. Hasil perhitungan penurunan program adalah grafik dengan warna hitam dengan penurunan akhir sebesar $642 \mathrm{~mm}$. Kurva yang didapat dari metode soft soil lebih menyerupai kurva penurunan asli, dibandingkan dengan metode Mohr-Coulomb.

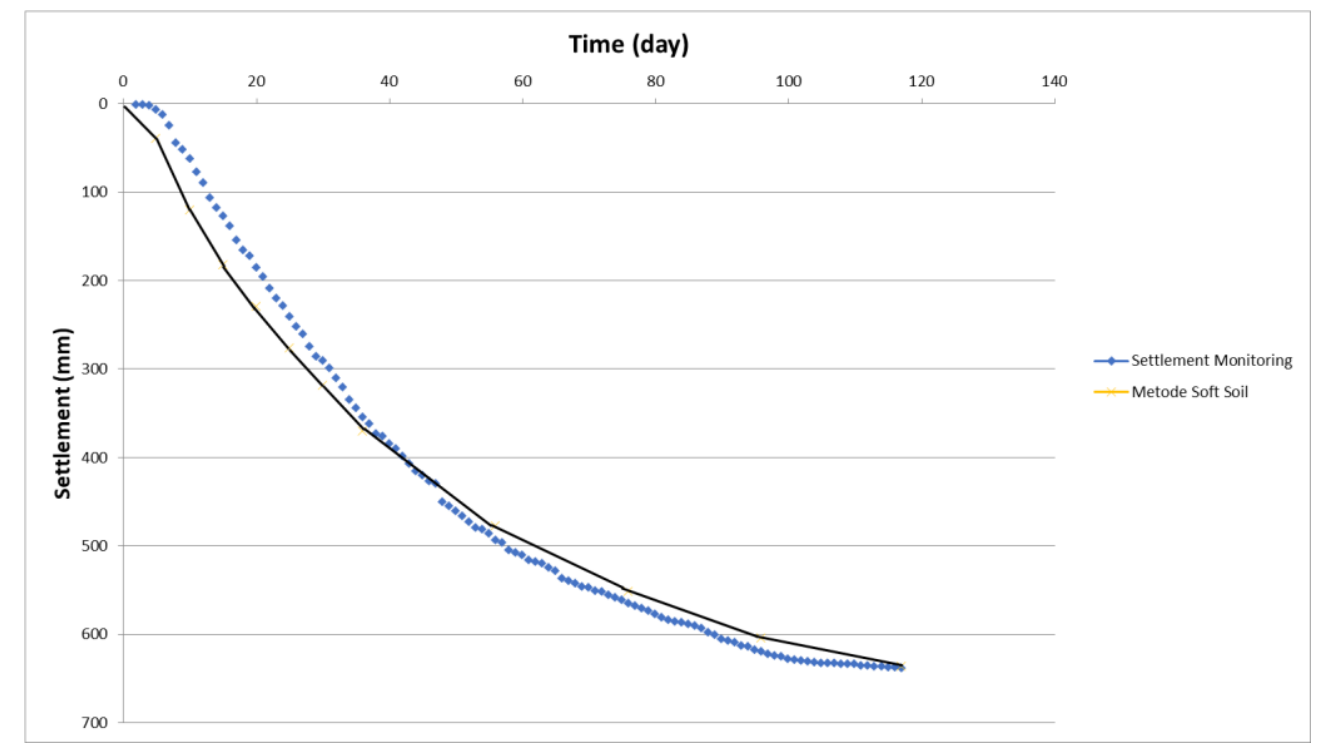

Gambar 6. Perbandingan penurunan monitoring lapangan dengan penurunan program elemen hingga 2D dengan metode soft soil

\section{Perhitungan metode Asaoka}

Metode observasi Asaoka adalah salah satu metode yang digunakan untuk memprediksi besarnya penurunan akhir (final settlement). Tabel 9 adalah data penurunan yang dimasukkan ke dalam kurva asaoka, dengan interval waktu yang digunakan adalah 20 hari.

Tabel 9. Data penurunan metode Asaoka

\begin{tabular}{cc}
\hline Hari & $\begin{array}{c}\text { Penurunan } \\
(\mathbf{m m})\end{array}$ \\
\hline 1 & 0 \\
20 & 184,5 \\
40 & 384 \\
60 & 510 \\
80 & 576,5 \\
100 & 627 \\
117 & 637,5 \\
\hline
\end{tabular}

Setelah memasukkan nilai penurunan monitoring dengan interval setiap 20 hari, dibuat garis 45 derajat pada grafik asaoka. Lalu masukkan $\rho n-1$ pada sumbu x yang merupakan nilai penurunan pada 1 periode sebelumnya, dan nilai on pada sumbu y yang merupakan nilai penurunan pada periode tersebut. Kemudian menarik garis regresi antara titik-titik penurunan tersebut hingga memotong garis 45 derajat. 


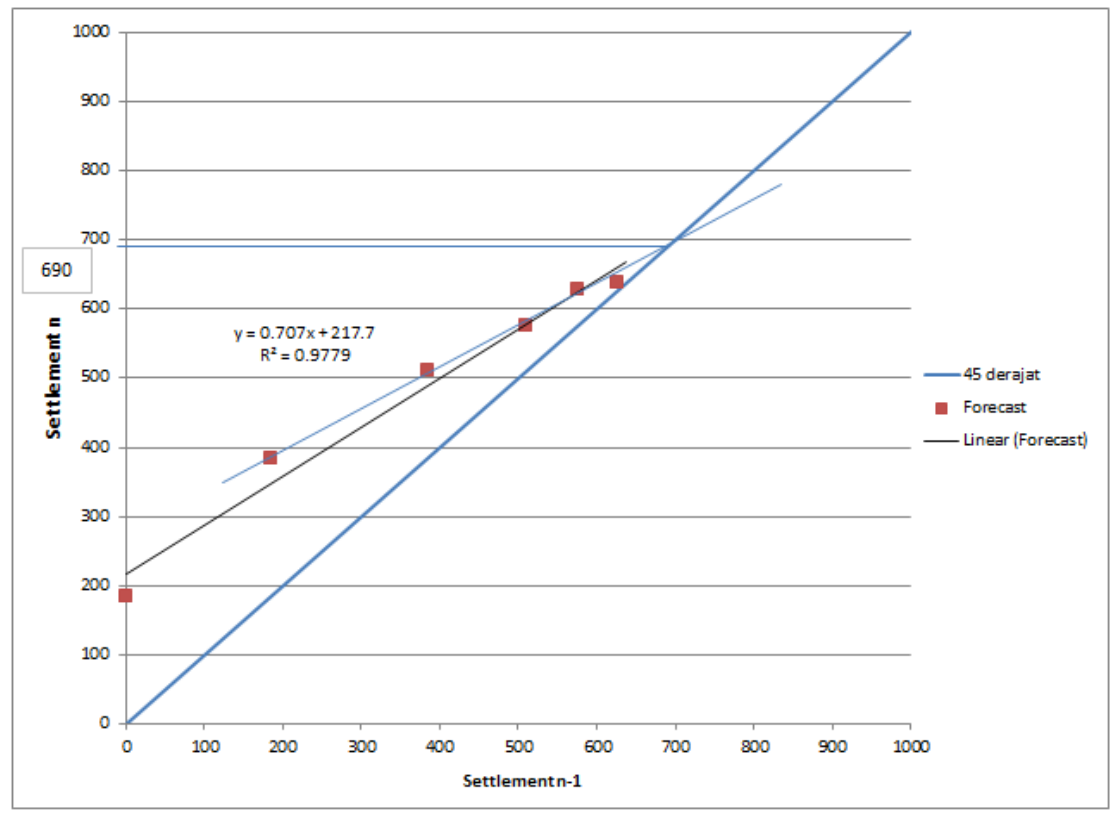

Gambar 7. Grafik penurunan metode Asaoka

Letak berpotongan kedua garis merupakan besar penurunan yang dinilai sebagai tanah terkonsolidasi 100\%. Dapat dilihat pada Gambar 7 didapat garis berpotongan pada saat penurunan sebesar 690mm. Dengan begitu dapat diketahui pada saat tanah terkonsolidasi $90 \%$ mengalami penurunan sebesar $621 \mathrm{~mm}$. Pada Gambar 8 didapat waktu yang dibutuhkan untuk mencapai tanah terkonsolidasi 90\% adalah 101 hari.

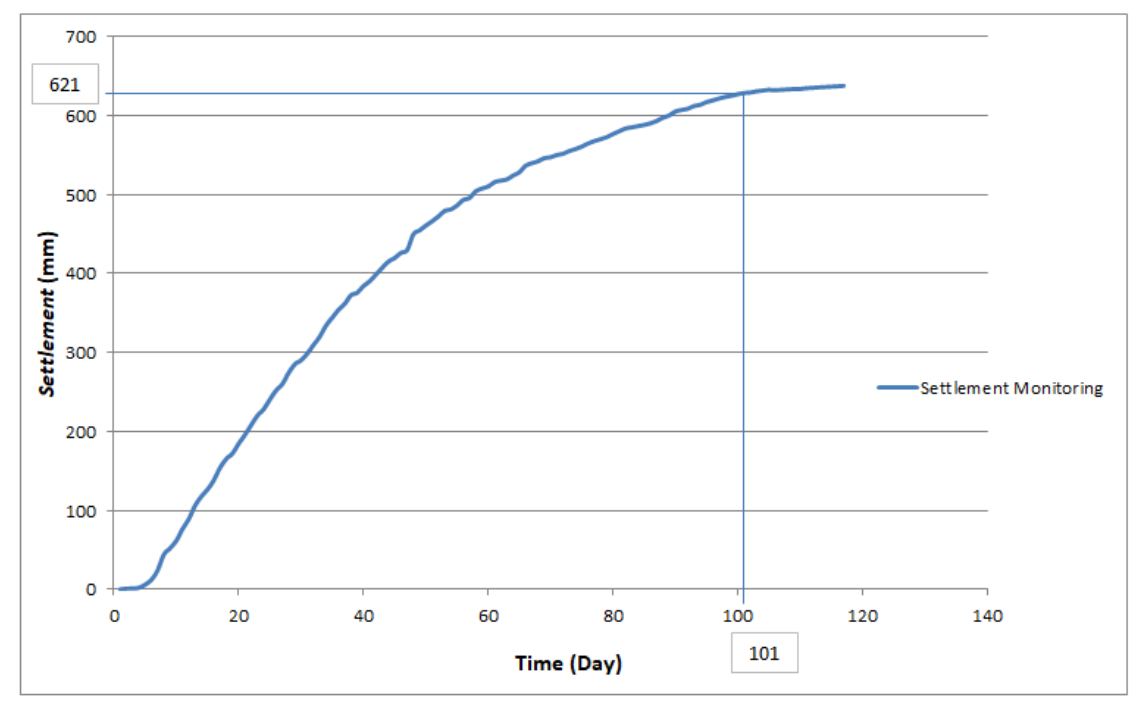

Gambar 8. Grafik penurunan monitoring dengan penurunan t90

\section{KESIMPULAN DAN SARAN}

\section{Kesimpulan}

Berdasarkan analisis terhadap perbaikan tanah pada jalan tol pada lahan reklamasi dengan program elemen hingga, didapatkan beberapa kesimpulan sebagai berikut:

1. Berdasarkan 3 hasil perhitungan penurunan, menggunakan program elemen hingga dengan metode $M o h r$ Coulomb dan soft soil, metode perhitungan manual didapatkan hasil yang paling mendekati hasil monitoring adalah hasil menggunakan metode soft soil. (Metode soft soil $=636 \mathrm{~mm}$, hasil monitoring = $638 \mathrm{~mm})$.

2. Berdasarkan metode Asaoka didapatkan, durasi tanah terkonsolidasi 90\% terjadi pada hari ke 101. 
Pemodelan Studi Kasus Vacuum Preloading untuk Andi Sulistio, et al. Memprediksi Penurunan Berdasarkan Data Pengamatan pada Tanah Reklamasi

3. Besar penurunan perhitungan secara manual lebih besar daripada besaran penurunan hasil program elemen hingga. Besar penurunan perhitungan manual $=732 \mathrm{~mm}$, sedangkan hasil penurunan menggunakan program elemen hingga dengan metode Mohr-Coulomb $=611 \mathrm{~mm}$, metode soft soil $=636 \mathrm{~mm}$.

\section{Saran}

Berdasarkan hasil analisis yang telah dilakukan, adapun saran untuk melengkapi studi ini adalah:

1. Melakukan analisis menggunakan program elemen hingga 3D agar hasil yang didapat lebih mendekati dengan kejadian lapangan.

2. Disarankan untuk melakukan meshing yang lebih detail agar mendapatkan hasil yang lebih akurat.

\section{DAFTAR PUSTAKA}

Bergardo, D. B. "Prefabricated Vertical Drains (PVD) in Soft Clay: A Case Study of the New Bangkok International Airport Project Vol.39." Canadian Geotechnical Journal (2002): 304-315.

Chai, J.C. S.L. "Simple Method of Modeling PVD-Improved Subsoil Vol.127, No.11." Journal of Geotechnical dan Geoenvironmental Engineering, ASCE (2001): 965-972.

Das, M. Braja. Mekanika Tanah (Prinsip-prinsip Rekayasa Geoteknik), Jilid 1. Jakarta: Erlangga, 1995.

Sakleshpur, V. A., Prezzi, M., Salgado, R. "Ground Engineering using Prefabricated Vretical Drains.” Geotechnical Engineering Journal. Purdue University. (2018).

Terzaghi, K. Peck, R. Mekanika Tanah dalam Praktek Rekayasa Jilid 1. Jakarta: PT. Gramedia Pustaka Utama, 1965. 